\title{
Patients lost to follow-up after midurethral sling surgery: How are they?
}

\author{
Myong Kim¹, Jung Hoon Lee ${ }^{1}$, Kyoungrok Kim¹, Sung Yong Cho², Hwancheol Son² \\ ${ }^{1}$ Department of Urology, Seoul National University Hospital, Seoul, Korea \\ ${ }^{2}$ Department of Urology, SMG-SNU Boramae Medical Center, Seoul, Korea
}

\section{ABSTRACT}

Purpose: To assess the ratio of patients lost to follow-up (FU) after midurethral sling surgery, to evaluate their success rate and current status, and to identify the reasons for FU loss.

Materials and Methods: Two-hundred thirty-eight patients who received trans-obturator tape (TOT) surgery were reviewed. For patients lost to FU within 3 months, Stamey's outcome questionnaire and questions regarding the reasons for FU loss were submitted via phone interview.

Results: One hundred forty-three (60.1\%) patients (FU loss group) were lost to FU within 3 months postoperatively. In the FU loss group, phone interviews were conducted with $117(81.8 \%)$ patients. Aside from the urgency rate (59.3\% vs. 72.3\%, p=0.049), there were no significant statistical differences in preoperative profiles between two group. The success rate of the FU loss group (80.3\%, 94 of 117 patients) was lower than that of the FU group (95.8\%, 91 of 95 patients) ( $p=0.001)$. The success rates in the FU loss group with mixed urinary incontinence (MUI) were significantly lower than in the FU group with MUI. As for the reason for FU loss, 74 patients $(62.7 \%)$ were lost due to incontinence improvement, 19 patients (16.1\%) cited personal problems, and 5 patients forgot the next follow-up date. Only 10 patients gave up further treatment despite their persisting incontinence.

Conclusions: In our study, more than half of patients were lost to follow-up after midurethral sling surgery. The FU loss group showed a lower surgical success rate, particularly with MUI. Close FU is recommended for better consultation of patients' incontinence.

\section{INTRODUCTION}

Stress urinary incontinence (SUI) is a widespread problem estimated to affect over $26 \%$ of middle-aged women in America and it induces social, sanitary, and psychological problems related to the patients' quality of life (1). Recently, considerable progress has been made toward treatments of SUI stemming from advances in understanding the pathogenesis (2-5). Various new surgical tre-

\section{ARTICLE INFO}

\section{Key words:}

Urinary Incontinence; Suburethral Slings; Treatment Outcome; Questionnaires

Int Braz J Urol. 2014; 40: 802-9

Submitted for publication:

April 03, 2014

Accepted after revision:

October 19, 2014 
cations such as bladder or bowel injuries. In less than ten years, these MUSSs spread worldwide. Various studies have demonstrated that all types of MUSSs have equivocally high long-term treatment rates, as well as low complication rates (10-13).

In clinical practice, however, it has been our empiric observation that a considerable fraction of SUI patients are lost to follow-up after MUSSs. Most previous reports have disregarded the results of those lost to regular follow-up (14-17), and there is relatively little information in the literature regarding missing patients after MUSSs. We hypothesized that these follow-up loss patients may have different results after MUSSs.

To test this hypothesis, we contacted our follow-up loss patients by telephone. We investigated the reasons for follow-up loss and the treatment success rate in these patients.

\section{MATERIALS AND METHODS}

A retrospective analysis was conducted of all patients who underwent outside-in type TOT (Monarc ${ }^{\circledR}$; AMS Inc., MN, USA) by single surgeon (Son H) between January 2003 and December 2008 for SUI. The study group included 238 women with a mean age of $55.8( \pm 9.7, S D)$ years. The protocol of the current study was approved by the Institutional Review Board of SMG-SNU Boramae Medical Center, Seoul, Korea (IRB No. 06-2009-28).

The operative technique was modified from DeLorme et al. $(18,19)$. The patients were put in lithotomy position. A vertical midline vaginal incision was made and the peri-urethral tissue was dissected laterally from the incision. Bilateral puncture incisions were made lateral to the ischiopubic ramus. The tunneller was introduced through the skin incision and crossed the obturator membrane. The index finger was placed into the vaginal incision to guide the tunneller. The end of the tape was introduced into the eye of the needle and then pulled through to place it behind the urethra without tension. The vaginal incision was repaired, and the Foley catheter and the vaginal gauze packing were indwelling until the first postoperative day.

Based on follow-up records, patients were divided into two groups: the follow-up loss group
(FU loss group) with loss within 3 months after the surgery and the follow-up group (FU group) with current follow-up. The following preoperative parameters were collected from the clinical records: age, body mass index (BMI), comorbidity, previous gynecologic surgery, symptom duration, symptom severity, International Prostate Symptom Score (IPSS), voiding diary, urinalysis, uroflowmetry (UFM) with post-void residual volume (PVR), $1 \mathrm{hr}$ pad test and Q-tip, and urodynamic study findings, including valsalva leak point pressure (VLPP) and cough leak point pressure (CLPP).

The routine interval for follow-up was 1, 3, 6 and 12 months after the surgery. Careful interviews, UFM and PVR measurement were performed in the FU group. Additional telephone interviews were conducted for the FU loss group. The questionnaires used in the phone interview were written at our institute (Table-1). Questionnaires were designed in previous studies to determine the following: the current states of SUI, the reason for follow-up loss, subjective satisfaction, and complications after the surgery in the FU loss group (20-24).

Surgical outcomes were grouped into $3 \mathrm{ca}-$ tegories according to the continence grading described by Stamey (25). These were as follow: cure, defined as a no leakage of urine; improvement, defined as minimal leakage without subjective discomfort; and failure, defined as no change in incontinence or with subjective discomfort. Treatment success was defined as the cure or improvement of presenting symptoms by the time of this survey.

The patients' baseline characteristics, preoperative data, and surgery outcomes were compared between the two groups. We also analyzed the reasons for the follow-up loss in the FU loss group by referring to the results of questionnaire. Comparisons between the two groups were made with the Student's t-test or paired t-test for continuous variables, chi-square or Mann-Whitney U test for nominal variables using SPSS ${ }^{\circledR}$ (version 21.0; IBM, NY, USA). All p-values were two-sided with significance considered at $p<0.05$.

\section{RESULTS}

Of the 238 treated patients, 143 (60.1\%) were allocated to the FU loss group and 95 (39.9\%) 
Table 1 - Telephone interview questionnaire for follow-up loss group.

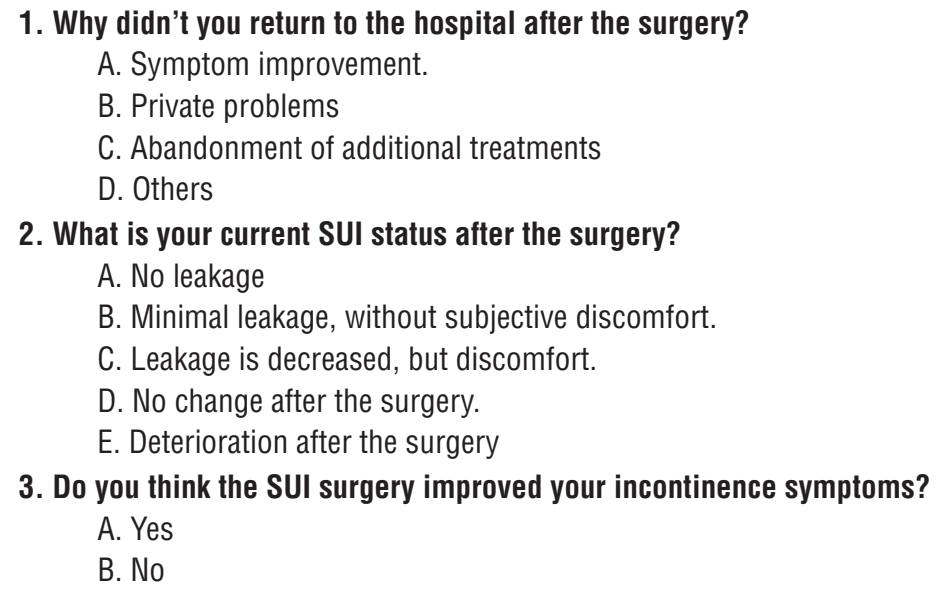
4. Are you satisfied with the outcomes after the surgery?
A. Yes.
B. No.

5. Did you have any other complications after the surgery?

to the FU group. Mean time from surgery was 19.6 $( \pm 9.9)$ months for FU loss group vs. $26.76( \pm 12.7)$ for FU group. There were no significant differences between the two groups in baseline characteristics and preoperative findings except in the comorbid urgency rate. The compared parameters included age, BMI, symptom duration, symptom severity, comorbid urgency or urge incontinence, previous surgery, IPSS, preoperative UFM with PVR, $1 \mathrm{hr}$ pad test, and urodynamic study findings. Detailed data for the two groups are shown in Table-2.

$120(83.9 \%)$ of the 143 FU loss patients were contacted for the telephone interview. Two patients refused to respond, and one patient had died before the interview for reasons unrelated to the TOT procedure. Consequently, 117 patients $(81.8 \%)$ in the FU loss group were interviewed. The overall treatment success rate in the FU group was 95.8\% [91 of 95 patients, "cure" in 78 (82.1\%) and "improvement" in 13 (13.7\%)]. FU group showed significant improvement of IPSS-total (sum of question 1 to $7 ; 20.5$ vs. $6.9, p<0.001$ ), IPSS-voiding (sum of question $1,3,5$, and $6 ; 10.0$ vs. $2.5, p$ $<0.012$ ) , IPSS-storage (sum of question 2, 4, and 7 ; 10.5 vs. $2.5, \mathrm{p}<0.001$ ), and IPSS-QoL (quality of life question score; 4.8 vs. $1.5, \mathrm{p}<0.001$ ), respectively (table was not given). According to the interview responses from the FU loss group, the success rate was 80.3\% [94 of 117 patients, cure in $82(70.1 \%)$ and improvement in $12(10.2 \%)]$. There was a statistical difference in treatment success rates between the two groups $(\mathrm{p}=0.001)$ (Table-3).

The status of SUI could be determined in 212 patients (95 in the FU group, and 117 in the FU loss group). In 204 of the 212 patients, the presence of preoperative urgency and urge incontinence was identified through review of medical records. The 204 identified patients were classified into two subgroups: stress type incontinence and mixed type incontinence. In each subgroup, the treatment success rates for the FU group and the FU loss group were compared. Among the $131 \mathrm{pa}-$ tients in the mixed type incontinence subgroup, there was a significant difference in success rate (95.5\% in FU group vs. 76.6\% in FU loss group, $\mathrm{p}=0.002$ ). However, among the 73 patients in the stress type incontinence subgroup, there was no statistically significant difference $(96.3 \%$ in FU group vs. 82.6\% in FU loss group, $\mathrm{p}=0.086$ ) (Table-4).

In the FU loss group, the reasons for follow up loss were identified for 118 patients (117 responders plus one deceased person) (Table-5). Seventy-four patients (62.7\%) did not follow up 
Table 2 - Baseline characteristics and preoperative findings.

\begin{tabular}{|c|c|c|c|}
\hline & FU loss group & FU group & $P^{*}$ \\
\hline No. of patients & 143 & 95 & - \\
\hline Mean age $( \pm S D$, years $)$ & $55.8( \pm 9.6)$ & $55.9( \pm 9.8)$ & 0.929 \\
\hline $\mathrm{BMI}\left( \pm \mathrm{SD}, \mathrm{kg} / \mathrm{m}^{2}\right)$ & $25.3( \pm 3.4)$ & $25.2( \pm 3.1)$ & 0.800 \\
\hline DM, HTN (\%) & $44(30.8 \%)$ & $37(38.9 \%)$ & 0.192 \\
\hline Gynecologic operation (\%) & $18(12.6 \%)$ & $12(12.6 \%)$ & 0.992 \\
\hline Symptom duration $( \pm S D$, months $)$ & $56.3( \pm 56.4)$ & $65.9( \pm 63.8)$ & 0.250 \\
\hline Median Stamey grade (range) & $2(1-3)$ & $2(1-3)$ & 0.987 \\
\hline Urgency (\%) & 80 of $135(59.3 \%)$ & 68 of $94(72.3 \%)$ & 0.042 \\
\hline Urge incontinence (\%) & 65 of $135(48.1 \%)$ & 57 of $94(60.6 \%)$ & 0.062 \\
\hline IPSS-total $( \pm S D)$ & $15.5( \pm 9.3)$ & $17.8( \pm 8.1)$ & 0.464 \\
\hline IPSS-voiding ( \pm SD) & $7.9( \pm 6.5)$ & $9.1( \pm 5.4)$ & 0.193 \\
\hline IPSS-storage $( \pm S D)$ & $7.5( \pm 4.0)$ & $8.7( \pm 3.8)$ & 0.115 \\
\hline IPSS-QoL $( \pm S D)$ & $4.0( \pm 1.6)$ & $4.2( \pm 1.3)$ & 0.367 \\
\hline $\operatorname{MUCP}\left( \pm \mathrm{SD}, \mathrm{cm} \mathrm{H}_{2} \mathrm{O}\right)$ & $56.5( \pm 22.9)$ & $52.8( \pm 21.4)$ & 0.213 \\
\hline $\mathrm{MCC}( \pm \mathrm{SD}, \mathrm{mL})$ & $407.0( \pm 85.3)$ & $384.6( \pm 100.6)$ & 0.133 \\
\hline $\operatorname{VLPP}\left( \pm \mathrm{SD}, \mathrm{cm} \mathrm{H} \mathrm{H}_{2} \mathrm{O}\right)$ & $85.9( \pm 32.7)$ & $85.1( \pm 27.6)$ & 0.838 \\
\hline $\mathrm{CLPP}\left( \pm \mathrm{SD}, \mathrm{cm} \mathrm{H}{ }_{2} \mathrm{O}\right)$ & $101.5( \pm 36.5)$ & $104.1( \pm 34.0)$ & 0.590 \\
\hline $\mathrm{Q}-\max ( \pm \mathrm{SD}, \mathrm{mL} / \mathrm{sec})$ & $33.5( \pm 29.2)$ & $31.7( \pm 19.9)$ & 0.577 \\
\hline Q-tip $>30^{\circ}(\%)$ & 59 of $140(42.1 \%)$ & 30 of $94(31.9 \%)$ & 0.131 \\
\hline 1hr Pad test $( \pm S D, g m)$ & $48.8( \pm 58.5)$ & $39.3( \pm 37.7)$ & 0.152 \\
\hline Voided volume $( \pm \mathrm{SD}, \mathrm{mL})$ & $228.8( \pm 102.7)$ & $243.2( \pm 98.4)$ & 0.278 \\
\hline PVR volume $( \pm \mathrm{SD}, \mathrm{mL})$ & $21.4( \pm 63.2)$ & $23.0( \pm 37.3)$ & 0.825 \\
\hline $\mathrm{FBC}( \pm \mathrm{SD}, \mathrm{mL})$ & $379.9( \pm 131.7)$ & $380.6( \pm 136.6)$ & 0.972 \\
\hline
\end{tabular}

FU loss group = follow-up loss group; FU group = follow-up group; $\mathbf{B M I}=$ Body mass index; IPSS = International Prostate Symptom Score; IPSS-total = sum of question 1 to 7; IPSS-voiding = sum of question 1, 3, 5, and 6; IPSS-storage = sum of question 2, 4, and 7; IPSS-Q $\mathbf{0 L}=$ quality of life question score; $\mathbf{M C C}=$ maximal cystometric capacity; VLPP = valsalva leakage point pressure; $\mathbf{C L P P}=$ cough leakage point pressure; $\mathbf{Q}$ - $\mathbf{m a x}=$ peak flow rate on uroflowmetry; $\mathbf{P V R}=$ volume, post-void residual urine volume; $\mathbf{F B C}=$ functional bladder capacity; ${ }^{*}$ = by Student's t-test (continuous variable), chi-square test (binary categorical variable), and Mann-Whitney U test (categorical variable more than three)

Table 3 - Outcome of the surgical procedure in two groups.

\begin{tabular}{lcc}
\hline Outcome & FU loss group & FU group \\
\hline Cure & $82(70.1 \%)$ & $78(82.1 \%)$ \\
Improvement & $12(10.2 \%)$ & $13(13.7 \%)$ \\
Failure & $23(19.7 \%)$ & $4(4.2 \%)$ \\
\hline Total & $117(100 \%)$ & $95(100 \%)$ \\
\hline
\end{tabular}

FU loss group = follow-up loss group; FU group = follow-up group 
Table 4 - Treatment success rate for the two groups stratified by accompaning symptoms.

\begin{tabular}{llcc}
\hline & FU loss group & FU group & $P$ \\
\hline Mixed type incontinence & $76.6 \%(n=64)$ & $95.5 \%(n=67)$ & 0.002 \\
Stress type incontinence & $82.6 \%(n=46)$ & $96.3 \%(n=27)$ & 0.086 \\
\hline
\end{tabular}

FU loss group = follow-up loss group; FU group = follow-up group

Table 5 - Reasons for follow-up loss after the mid-urethral sling surgery.

\begin{tabular}{lcc}
\hline Reason & $\mathrm{N}$ & Percent \\
\hline Symptom improvement & 74 & $62.7 \%$ \\
Personal problem & 19 & $16.1 \%$ \\
Abandonment of additional treatment & 10 & $8.5 \%$ \\
Oblivion of the follow-up date & 5 & $4.2 \%$ \\
Death & 1 & $0.8 \%$ \\
Other reasons & 9 & $7.6 \%$ \\
\hline Total & 118 & 100 \\
\hline
\end{tabular}

because of symptom improvement. Other patients were lost due to private matters, including 19 (16.1\%) patients with financial or private problems and 10 patients (4.2\%) who abandoned additional treatment despite their ongoing incontinence. Five patients (4.2\%) forgot the follow-up dates. Among the 117 responders in the FU loss group, 98 patients $(83.8 \%)$ thought that TOT improved their symptoms, and 85 patients (72.6\%) were satisfied with the outcome of the surgery. Two patients (1.7\%) experienced de novo urgencies after surgery.

\section{DISCUSSION}

This study showed that $60.1 \%$ of patients with TOT for SUI were lost to follow-up within 3 months. There are not many reports about follow-up loss after MUSSs, but a few studies reported 27 to $31 \%$ loss rate within 3 months $(26,27)$. Ou et al. [28] performed systematic review of 58 prospective SUI surgery series and reported 36\% follow-up loss at 36 months after surgery. Our loss rates were higher than those of previous reports. The cultural differences, the educational and financial statuses of local populations, the differences in the medical systems, and the intensity of follow-up recommendation between clinical studies and real practices could be reasons for the differences in follow-up rates. In real-life practice, stress urinary incontinence is not a life-threatening disease; thus the discrepancy of follow-up compliance may be exaggerated.

Many factors may have influenced the patients who did not follow-up. Symptom improvement after surgery is postulated as the major cause. Indeed, our findings show that $62.7 \%$ patients are lost to follow-up because of symptom improvement (Table-5). These results are in close agreement with Ballert et al. (26), suggesting that a substantial portion of patients lost to follow-up were satisfied with treatment and discontinued the planned follow-up by their own decision. In the current study, personal problems such as busyness or financing problems were the second largest (16.7\%) causes. However, a considerable fraction of these patients may have experienced symptom improvement. Such improvement might 
have promoted the follow-up loss because of their private problems. Even though the number of such cases was low, some patients (4.2\%) were lost to follow-up because they had forgotten their next appointment dates. In practice, patients could be reminded of the next follow-up appointment. However, a considerable portion of patients abandoned their further treatment despite their remaining symptoms. Some may have visited other hospitals.

Evidence continues to accumulate indicating that the overall outcomes of MUSSs are excellent. In outside-in type TOT, well-designed prospective studies have shown that the treatment success rate is $86 \%$ to $94 \%$ in up to 4 -year follow-up (14-16). However, all these studies reported some fraction of follow-up loss (4\% to $14 \%$ ) and missing data were excluded from the analyses (complete case analysis). However, processing the missing data is a complicated issue. Karl et al.(29) recommended considering the full range of best (all cases are successes) and worst (all cases are failures) scenarios in handling loss of follow-up data. In this manner, Ward et al. $(30,31)$ reported an extremely broad range of success rates after TVT: $63 \%$ to $85 \%$ in 2 years and $33 \%$ to $82 \%$ in 5 years. Ou et al. (28) pointed out that only 7 of 58 SUI prospective studies considered the missing data as failure. This exclusivity of complete case analysis may exaggerate the outcomes of MUSSs.

In our analysis, the overall treatment success rate was 95.8\% in the FU group (Table-2). This result is consistent with previous TOT series. However, we found a significant difference in the treatment success rates between the FU group and FU loss group, (95.8\% vs. 80.3, p=0.001). In a previous study, Ballert et al. (26) concluded that there are no significant differences in success rates (follow-up loss vs. follow-up: 73\% vs. $81 \%$, $\mathrm{p}=0.39$ ). However, they were only able to contact about two-thirds of follow-up loss patients. We had a higher response rate of follow-up loss patients (81.8\%). The results of the present study correspond with the results from Minassian et al.(27), which reported that follow-up loss patients had lower success rates (72.4\% vs. $92.4 \%, \mathrm{p}=0.006)$.

SUI subtypes were not considered in previous studies $(26,27)$. To clarify this point, the patients were classified in two subgroups: mixed type incontinence and stress type incontinence. In mixed type incontinence, there was a statistically significant difference in success rates between the two groups ( $95.5 \%$ vs. $76.6 \%, p=0.002)$. In stress type incontinence, however, there was no significant difference $(\mathrm{p}=0.086)$. These results are in agreement with those of a previous study reporting that more than half of treatment failure patients in the follow-up loss group had a higher urge score ratio than stress score ratio based on the Medical, Epidemiological and Social Aspects of Aging (MESA) questionnaire [26]. We postulated that, in the FU group, the remnant urgency or urge incontinence after MUSS may be settled by additional treatment; on the other hand, in the FU loss group, these supplementary aids were not utilized. With these findings, we suggest that the mixed type incontinence patients need to be followed more closely than simple stress type incontinence patients.

In our experience with the telephone interview with follow-up loss patients, in the event of successful contact, nearly all patients responded well to the survey (98.3\% 117 of 119). The merit of the telephone interview is that the current states of follow-up loss patients were determined with ease. We simplified the questionnaires to optimize the response. However, our study design has an important limitation in that the results are dependent on the patients' replies, without any objective findings. Another limitation of the current study is the relatively high rate of follow-up loss. Possible reasons for this higher incidence were mentioned above. The retrospective study is also a pitfall. However, by simplifying the study design, we could identify the current status of most patients who were lost to follow-up after MUSS and thus fulfill our initial purpose. Patients lost to follow-up after MUSSs are often excluded because of the difficulty in identifying their current status. As a result, there is relatively little information in the literature regarding these follow-up loss patients. Our current study reconsidered these neglected patients. Further long-term and intensive studies are required to assess these follow-up loss patients. Furthermore, the status of FU loss patients must be considered in order to study the long-term outcomes of the MUSSs. 


\section{CONCLUSIONS}

The current study demonstrated that a considerable fraction of patients were lost to follow up 3 months after MUSSs. Moreover, there was a significant difference in treatment success rate, especially between the FU and FU loss groups in the mixed type incontinence subgroup. Based on these findings, we recommend that mixed type incontinence patients should be followed up more closely.

\section{ABBREVIATIONS}

SUI $=$ stress urinary incontinence

MUSS $=$ mid-urethral sling surgery

SPARC $=$ suprapubic arc

TOT $=$ trans-obturator vaginal tape

$\mathrm{FU}=$ follow-up

$\mathrm{BMI}=$ body mass index

UFM = uroflowmetry

PVR = post-void residual volume

VLPP = Valsalva leak point pressure

CLPP $=$ cough leak point pressure

MESA = Medical, Epidemiological and Social Aspects of Aging

\section{CONFLICT OF INTEREST}

None declared.

\section{REFERENCES}

1. Iosif CS, Bekassy Z, Rydhstrom H: Prevalence of urinary incontinence in middle-aged women. Int J Gynecol Obstet. 1988;26:255-9.

2. Petros PE, Ulmsten UI: An integral theory and its method for the diagnosis and management of female urinary incontinence. Scand J Urol Nephrol Suppl 1993;153:1-93.

3. Petros PE, Ulmsten U: Urethral pressure increase on effort originates from within the urethra, and continence from musculovaginal closure. Neurourol Urodyn 1995;14:337-46; discussion 346-50.

4. Petros PE, Ulmsten U: Urethral and bladder neck closure mechanisms. Am J Obstet Gynecol 1995;173:346-8.

5. Haab F, Zimmern PE, Leach GE: Female stress urinary incontinence due to intrinsic sphincteric deficiency: recognition and management. J Urol 1996;156:3-17.
6. Ulmsten U, Petros P: Intravaginal slingplasty (IVS): an ambulatory surgical procedure for treatment of female urinary incontinence. Scand J Urol Nephrol 1995;29:75-82.

7. Delorme E: Transobturator urethral suspension: miniinvasive procedure in the treatment of stress urinary incontinence in women. Prog Urol 2001;11:1306-13.

8. Deval B, Levardon M, Samain E, Rafii A, Cortesse A, Amarenco $G$, et al.: A french multicenter clinical trial of SPARC for stress urinary incontinence. Eur Urol 2003;44:254-9.

9. Kassardjian ZG: Sling procedures for urinary incontinence in women. BJU Int 2004:93:665-70.

10. Nilsson CG, Palva K, Rezapour M, Falconer C: Eleven years prospective follow-up of the tension-free vaginal tape procedure for treatment of stress urinary incontinence. Int Urogynecol J 2008;19:1043-7.

11. Angioli R, Plotti F, Muzii L, Montera R, Panici PB, Zullo MA: Tension-free vaginal tape versus transobturator suburethral tape: Five-year follow-up results of a prospective, randomised trial. Eur Urol 2010;58:671-7.

12. Nazemi TM, Yamada B, Govier FE, Kuznetsov DD, Kodama K, Kobashi KC: Minimum 24-month followup of the sling for the treatment of stress urinary incontinence. J Urol 2008;179:596-9.

13. Novara G, Artibani W, Barber MD, Chapple CR, Costantini $\mathrm{E}$, Ficarra $\mathrm{V}$, et al:: Updated systematic review and metaanalysis of the comparative data on colposuspensions, pubovaginal slings, and midurethral tapes in the surgical treatment of female stress urinary incontinence. Eur Urol 2010; 58:218-38.

14. Houwert RM, Renes-Zijl C, Vos MC, Vervest HM: TVT-O versus Monarc after a 2-4-year follow-up: a prospective comparative study. Int Urogynecol J 2009;20:1327-33.

15. Liapis A, Bakas P, Creatsas G: Monarc vs TVT-O for the treatment of primary stress incontinence: a randomized study. Int Urogynecol J 2008;19:185-90.

16. Abdel-fattah M, Ramsay I, Pringle S, Hardwick C, Ali $H$, Young $D$, et al.: Randomised prospective singleblinded study comparing 'inside-out' versus 'outside-in' transobturator tapes in the management of urodynamic stress incontinence: 1-year outcomes from the E-TOT study. BJOG 2010;117:870-8.

17. Jun KK, Oh SM, Choo GY, Park HK, Paick SH, Lho YS, et al.: Long-term Clinical Outcomes of the Tension-free Vaginal Tape Procedure for the Treatment of Stress Urinary Incontinence in Elderly Women over 65. Korean J Urol 2012;53:184-8.

18. Delorme E, Droupy S, de Tayrac R, Delmas V: Transobturator tape (Uratape $\AA$ ): A new minimally-invasive procedure to treat female urinary incontinence. Eur Urol 2004;45:203-7.

19. Park YJ, Kim DY: Randomized controlled study of MONARC® vs. tension-free vaginal tape obturator (TVT-O®) in the treatment of female urinary incontinence: comparison of 3-year cure rates. Korean J Urol 2012;53:258-62. 
20. Abrams P, Avery K, Gardener N, Donovan J: The international consultation on incontinence modular questionnaire: www. iciq.net. J Urol 2006;175:1063-6.

21. Rutman M, Itano N, Deng D, Raz S, Rodríguez LV: Longterm durability of the distal urethral polypropylene sling procedure for stress urinary incontinence: minimum 5-year followup of surgical outcome and satisfaction determined by patient reported questionnaires. J Urol 2006;175:610-3.

22. Clemens JQ, Bushman W, Schaeffer AJ: Questionnaire based results of the bulbourethral sling procedure. J Urol 1999;162:1972-6.

23. Juma S, Brito CG: Transobturator tape (TOT): Two years follow-up. Neurourol Urodyn 2007;26:37-41.

24. Ullrich NF, Comiter CV: The male sling for stress urinary incontinence: 24-month followup with questionnaire based assessment. J Urol 2004;172:207-9.

25. Stamey TA: Endoscopic suspension of the vesical neck for urinary incontinence in females. Report on 203 consecutive patients. Ann Surg 1980;192:465-71.
26. Ballert KN, Rose AE, Biggs GY, Rosenblum N, Nitti VW: Outcomes of patients lost to followup after mid urethral synthetic slingsSuccesses or failures? J Urol 2010;183:1455-8.

27. Minassian VA, Al-Badr A, Pascali DU, Lovatsis D, Drutz HP: Tension-free vaginal tape: Do patients who fail to follow-up have the same results as those who do? Neurourol Urodyn 2005; 24:35-8.

28. Ou R, Xie X-J, Zimmern PE: Level I/II evidence-based studies of surgical treatment of female stress urinary incontinence: Patients lost to followup. J Urol 2011;185:1338-43.

29. Karl A, Akl EA, Moy ML, Dahm P: Evidence-based urology in practice: loss to follow-up. BJU int 2010;106:24-6.

30. Ward KL, Hilton P: A prospective multicenter randomized trial of tension-free vaginal tape and colposuspension for primary urodynamic stress incontinence: Two-year follow-up Am J Obstet Gynecol 2004;190:324-31

31. Ward KL, Hilton $P$ : Tension-free vaginal tape versus colposuspension for primary urodynamic stress incontinence: 5-year follow up. BJOG 2008;115:226-33.

Correspondence address:

Hwancheol Son, M.D., Ph.D.

Department of Urology, SMG-SNU Boramae Medical Center, Donggak-gu, Boramae-ro 5 Gil, 20 Seoul 156-707, Korea

Telephone: + 8228702391

E-mail: volley@snu.ac.kr 